\title{
Correctional labor as an alternative to imprisonment in modern problems of punishment assignment
}

\author{
Andrey Andreevich Baybarin ${ }^{1 *}$, Maria Ivanovna Sinyaeva ${ }^{1}$, Alina Igorevna \\ Levchenko $^{1}$, Dina Nikolaevna Sadchikova ${ }^{1}$, and Azamat Tynyshtykbayevich Aldabergenov ${ }^{2}$ \\ ${ }^{1}$ South-Western State University, Department of Criminal Law, Kursk, Russia \\ ${ }^{2}$ Makan Yesbulatov Almaty Academy of the Republic of Kazakhstan Ministry of Internal Affairs, \\ Training Center for Anti-Extremism Expert, Almaty, Kazakhstan
}

\begin{abstract}
The global practice has shown many times that the primary means of struggling with criminality over the entire history of the civilized society is punishment. The modern legislator is constantly striving to improve its types by following global trends in its regulation, assignment and use. Efficiency of labor influence over the convict makes us pay a special attention to punishments suggesting mandatory labor nurturing. One of such punishments is correctional labor whose relevance of research is caused by the interest of the international society to use measures alternative to imprisonment. Despite the fact that legal systems of some foreign countries envisage and widely use punishments whose various characteristics are similar to domestic correctional labor, the Russian experience of their regulation and use can be useful, due to their specific nature, and interesting to any modern state, because the issue of implementing a rich potential of penology is especially relevant these days. At the same time there are significant issues in assignment of correctional labor, which area caused by imperfect construction of law. Research purpose is to study urgent issues of assigning correctional labor as an alternative to imprisonment in the Russian legal system. Methods: the analysis method allowed for characterization of specific features of assigning criminal punishment in the form of correctional labor and revealing primary problems in this area. The comparative method was used to collate specifics of correctional labor and probation. The prediction method helped defining perspectives to eliminate the identified disadvantages. An alternative mode of correctional labor has been criticized; measures have been offered to improve the legislative regulation of correctional labor within Article 53.1 of the Russian Federation Criminal Code.
\end{abstract}

Keywords: correctional labor, alternative punishment sanction, humanism

\section{Introduction}

\footnotetext{
* Corresponding author: andrewbaybarin@gmail.com
} 
It is no secret that one of pre-requisites for achieving the purpose of any punishment is a legally correct and scientifically supported activity for its assignment. Despite the fact, that correctional labor in Russia has been applied for years by now (since January 1, 2017), we must pay attention to the fact that the current legal norms in this area are distinguished by challenges negatively affecting its normal use.

\section{Methods}

The analysis method allowed for characterization of specific features of assigning criminal punishment in the form of correctional labor and revealing primary problems in this area. The comparative method was used to collate specifics of correctional labor and probation. The prediction method helped defining perspectives to eliminate the identified disadvantages.

\section{$3 \quad$ Results}

Assignment of correctional labor in practice is related with serious problems caused by imperfection of the Russian criminal law. The provisions of the concept and specific features of correctional labor regulated by Article 53.1 RF CC (Russian Federation Criminal Code) contradict with some other norms of the General Part of RF CC, and sanction of some articles of the Special Part of RF CC frequently impede assignment of correctional labor.

\section{Discussion}

There is a lot of arguable issues in the legal nature and essence of correctional labor referred to as imprisonment alternatives (Article 53.1 RF CC) [1]. This legislative specification is a novelty of the Russian legislator that is incongruent, as we believe, with primary postulates of the criminal legal theory. The situations when the court opts for one of types of punishments envisaged for a specific crime provided there is an alternative sanction in the Special Part must be considered as an alternative choice. Moreover, all other types of punishment are alternative relative to imprisonment, since they are placed higher at the stairs of punishments. This gives rise to a question: why has the legislator emphasized correctional labor by pointing at their alternative nature? Many researchers state that this specification is excessive, among which are Brilliantov [2], Bush [3], Kupryachenik [4].

According to primary provisions of criminal law, the court can assign correctional labor just as any other punishment if its less strict type fails to ensure its statutorily established purposes (Part 1, Article $60 \mathrm{RF} \mathrm{CC)} \mathrm{[1].} \mathrm{In} \mathrm{relation} \mathrm{to} \mathrm{the} \mathrm{researched} \mathrm{punishment,} \mathrm{the} \mathrm{law}$ has defined a directly opposite norm that is not correlated with primary principles of its purpose: initially, the court takes a decision to assign imprisonment that is then substituted by correctional labor. Indeed, legal justifiability of such substituting nature of correctional labor causes doubt because the law requirement to assign a punishment and substitute it with a different one contradicts the rules of legal engineering [5].

It should be noted that the legislator has not directly prohibited the courts to assign correctional labor independently with no previously made decision of assigning imprisonment. Literal reading of the law, namely parts 1 and 2, Article 53,1 RF CC as well Clause 22.1 of the Decree of the Russian Federation Plenum of Supreme Court dated 22.12.2015 [6] states as follows: correctional labor is assigned of they are directly envisaged by sanctions of respective articles of the RF CC Special Part along with imprisonment.

Along with that, a detailed analysis of some articles of the RF CC Special Part (Part 1, Article 159.1, Part 1, Article 159.2, Part 1, Article 159.5, Part 1, Article 159.6, Part 1, Article 200.1, Part 2, Article 200.1, Part 1, Article 207, Part 5 and 6, Article 327.1 RF CC) shows 
the contrary: along with correctional labor defined in their sanctions, no imprisonment is envisaged. In such cases, as V.M. Stepashin indicates, it is impossible to assign punishment in the form of correctional labor [7]. Legal practice in such cases also tends to abandon direct assignment of correctional labor [8] that seems to be more reasonable. In the conditions of this legislative uncertainty, courts do not risk assigning correctional labor [9].

Legislative language of the essence of correctional labor causes another issue. Sanctions of a group of RF CC elements envisage that the term of this punishment is longer that the term of imprisonment (for example, the sanctions of Part 2, Article 121, Part 1, Article 135, Part 2, Article 1 RF CC). In this connection, it can be reasonable to conclude that such possibility must not be permitted.

In an opposite case, there is a paradox situation contradicting with criminal law postulates of punishment assignment because when judges decide whether to assign correctional labor or not, they face a dilemma. As an example, let us consider the sanction of Part 1, Article 135 RF CC that permits punishment in the form of correctional labor with the maximum possible term of 5 years but at the same time it defines the maximum imprisonment term of three years for the same actions. How the judge will solve the issue of substituting the punishment term in this case taking into account the nature of the considered punishment? The judge will have to ignore provisions of either General or Special Part of the Russian Federation Criminal Code. No unified legislative approach leads to disagreement of judicial authorities and violates basics of the criminal law science defining interrelations and unity of General and Special Part of the RF CC. Rarog calls unacceptable establishment of the scope of correctional labor in the sanctions of RF CC articles one of the most common systemic mistakes of the Russian legislator [10].

Another legislative gap complicating the process of applying correctional labor is caused by its tight relation with a popular practical measure of criminal legal nature referred to as probation. By including an alternative to imprisonment into the national criminal legal system, which is characterized by a much lower upper limit of the term, and by keeping the effect of the norms enacted by Article 73 RF CC concerning the possibility of probation, the legislator has put judicial authorities into contradictory conditions: all the rest being equal, they cannot take decision differing in severity of consequences. M.R. Geta and A.N. Smirnov pointed at the similarity of these measures and considered correctional labor as a hybrid of probation and punishment in the form of correctional labor [11]. A.V. Zvonov also pointed at the need to change the procedure of interaction between the system of criminal punishment and the system of other criminal legal measures [12].

In this connection, attention must be paid to a contradiction occurring in comparing correctional labor and probation. In case of a more detailed consideration of this issue, one must research procedural specifics of assigning probation, since this aspect of application of Article 73 RF CC deserves special attention within this research. Similar to correctional labor, we can distinguish several stages of probation assignment.

The essence of the first stage lies in the court obligation to justify the judgment made on assignment of imprisonment. Along with that, the second stage is characterized by the need to reason the court conclusion on convict correction with real imprisonment [13]. We see that similar features can be found in the procedural assignment of this criminal measure.

T.P. Butenko discussed the collision of correlation between correctional labor and probation given in the law. His conclusions show that it is unacceptable to apply imprisonment to a convict when assigning imprisonment for less than five years for committing a crime of low or medium gravity or for committing a serious crime for the first time because the law provides a more democratic alternative in the form of correctional labor [14].

This opinion is justified and reflected in the activity of law-enforcement authorities because courts having these equal conditions at the same time opt to substitute imprisonment 
with correctional labor according to Part 2, Article 53.1 RF CC [14]. In this manner, it is reasonable to make a conclusion that implementing a novelty of alternative substitutive nature of correctional labor into the applicable law significantly cuts off and reduces opportunities of applying probation.

The analysis of the above arguments allows asserting that the institute of probation must become void when the provisions of correctional become effective in the current conditions. This means its partial application - concerning persons condemned to imprisonment for less than 5 years for committing a crime of low or medium gravity or for committing a serious crime for the first time (except for persons to which it is prohibited to apply correctional labor).

Taking into account that the norms on probation are milder due to their legal specifics and humanistic nature, this proposal seems unreasonable within a common trend of humanization of criminal and criminal procedural law.

In this connection, the position of Golik seems to be just and valid -he proposed to disconnect correctional labor and probation at the legislative level by imparting individual specific features to each of these measures [15].

\section{Conclusion}

In this manner, the rules to assign punishment in the form of correctional labor that became effective on January 1, 2017, do not comply with basic criminal legal principles and postulates of punishment assignment. For example, we talk of the norms established in Article $60 \mathrm{RF}$ CC. Moreover, the analysis of Article 53.1 RF CC and law enforcement practice gives all grounds to believe that correctional labor cannot be assigned by the court as an individual type of punishment, and it must undergo specific stages to be assigned to the convict. The issues of practicability to impose contradictory sanctions related with correctional labor are also doubtful: their term is usually longer than imprisonment. Moreover, a legislative prescription of alternative nature of correctional labor washes out this type of punishment with probation impeding its normal implementation.

The issues found during the research have a negative effect on humanistic and perspective punishment in the form of correctional labor impeding its assignment by Russian courts.

To eliminate existing uncertainties, it seems reasonable to eliminate excessive wording from the legislative language of Part 1, Article 34 RF CC concerning the use of correctional labor as an alternative to imprisonment. Moreover, exclusion of Part 2 from Article 53.1 RF $\mathrm{CC}$ will allow eliminating an existing contradiction with general rules of punishment substitution.

It seems that these changes will promote improvement of correctional labor assignment mechanisms and further implementation of this punishment within a wide trend of humanization of criminal and criminal procedural law.

\section{References}

1. Ugolovnyi kodeks RF [RF Criminal Code] dated 13.06.1996 No. 63-FZ (Ed. 08.12.2020), Russian Federation Official Gazette, 25, 2954 (1996)

2. A.V. Brilliantov, Criminal Law, 6, 16-19 (2012)

3. V.V. Bush, Prinuditelnye raboty kak vid nakazaniya v ugolovnom prave Rossii [Correctional Labor as a Type of Punishment in Legal Law of Russia], PhD thesis in Legal Science (Stavropol, 2015)

4. O.S. Kupryachenik, Theory and Prac. of Soc. Dev. 5, 98-100 (2016)

5. T.V. Nepomnyaschaya, Herald of Omsk State Univ. Ser. Law 3(56), 148-152 (2018) 
6. Postanovlenie Plenuma Verkhovnogo Suda RF ot 22.12.2015 g. №58 O praktike naznacheniya sudami Rossiiskoi Federatsii ugolovnogo nakazaniya [Resolution of the Russian Federation Plenum of Supreme Court dated 22.12.2015 No. 58 On Practice of Assignment of Criminal Punishment by Russian Courts], Bul. RF Supreme Court 2 (2016)

7. V.M. Stepashin, Herald of Omsk State Univ. 4, 156-161 (2015)

8. Apellyatsionnoe postanovlenie Leninskogo raionnogo suda goroda Tambova ot 25 iyulya 2019 g. № 10-14/2019 [Appellate Resolution of the Leninsk District Court of Tambov dated July 25, 2019 No. 10-14/2019]. Accessed on: March 17, 2021. [Online]. Available: shorturl.at/aoFN5

9. S.N. Pomnina, A.A. Lavrushkina, Vestnik of Volzhskiy Univ. after V.N. Tatishev 4, 227-233 (2017)

10. A.I. Rarog, Rel. Prob. of Rus. Law 4(101), 95-103 (2019)

11. M.R. Geta, A.N. Smirnov, Bul. of the Kuzbass Inst. 1(34), 25-30 (2018)

12. A.V. Zvonov, Legal Sc. and Law-Enf. Prac. 4, 106-111 (2016)

13. R.Sh. Urazbayev, The Review of Ec., the Law and Soc. 3, 91-99 (2017)

14. T.P. Butenko, Man: Crime and Pun. 1, 89-91 (2014)

15. Yu.A. Golik, Crim. Law 2, 29-34 (2012) 